\title{
A ENFITEUSE E SEU VASTO ALCANCE SOCIAL
}

\author{
Geraldo Ferreira Lanfredi \\ Doutorando em Direito Civil pela Faculdade de Direito da \\ Universidade de São Paulo, juiz de Direito aposentado e advogado
}

\begin{abstract}
Resumo:
O autor aborda as características da enfiteuse, os direitos e deveres do enfiteuta e do senhorio e, por fim, destaca a necessidade de revitalização do instituto buscando promover o cultivo das terras improdutivas e o incentivo à agricultura no país.
\end{abstract}

Abstract:

The author's study is about of the characteristics of the emphyteusis, the rights and duties of the emphyteuta and of the lordship and, finally, it detaches the need of revitalization of the institute looking for to promote the cultivation of the unproductive lands and the incentive to the agriculture in the country.

Unitermos: enfiteuse; características; direitos e deveres do enfiteuta e do proprietário; revitalização.

1. Introdução

A enfiteuse, que também se denomina aforamento ou emprazamento, é um instituto contemplado no Código Civil brasileiro, recaindo sobre imóveis nãocultivados e nos quais não haja edificações (arts. 678 a 693).

Segundo o jurista Rubens Limongi França, "enfiteuse é o desmembramento da propriedade da qual resulta o direito real perpétuo, em que o titular (enfiteuta), assumindo o domínio útil da coisa, constituída de terras nãocultivadas ou terrenos por edificar (bem foreiro), é assistido pela faculdade de lhe fluir todas as utilidades, sem destruir a substância, mediante a obrigação de pagar ao nu-proprietário (senhorio direto), uma pensão anual invariável (foro)" 1

1. Rubens Limongi França, Manual de Direito Civil, Edit. RT., 1971, v. 3, p. 220. 
Este instituto jurídico é daqueles que guardam vinculação com as condições econômicas e sociais de cada época. No Brasil, graças à vasta extensão de nossas terras incultas e por falta de lavradores, sobretudo no século passado, o aforamento proporcionou frutos importantes, como a urbanização de áreas circunvizinhas aos grandes centros.

Segundo a maioria dos doutrinadores, o instituto está hoje em desuso, embora outros realcem o seu "longuíssimo alcance social" para formação de novos núcleos residenciais e coloniais no vasto território nacional, necessitando, para isso, de uma remodelação e adaptação às condições da vida moderna. ${ }^{2}$

\section{Elementos fundamentais}

Enfiteuta ou foreiro, denominado, ainda, de senhorio útil, é, portanto, a pessoa que recebe do proprietário o imóvel, a fim de usar dele como se fora seu, comprometendo-se a pagar àquele, cada ano, pensão determinada, cujo valor não poderá sofrer alteração. Nu-proprietário ou senhorio direto, também chamado enfiteuticador, é a pessoa que, nessa relação, transfere o direito sobre o imóvel, menos o domínio. Enfiteuse é o contrato que assim se perfaz.

O senhorio direto é o que tem a propriedade do imóvel aforado e está dele afastado, não tendo a posse direta.

Traço peculiar e essencial do aforamento é a perpetuidade, sem o qual o instituto não passaria de mero arrendamento (Código Civil, art. 679).

Terrenos cultivados ou construídos não mais podem ser objeto de aforamento.

Sem a pensão ou foro, a enfiteuse não se caracteriza.

\section{Condições essenciais para constituir o aforamento}

Para ser constituída uma enfiteuse, é necessário e indispensável: 1 a existência de um contrato entre o senhorio direto e o enfiteuta; 2 a condição de proprietário da parte do senhorio direto, pois quem não é proprietário do imóvel, porque não-registrado em seu nome, não pode constituir enfiteuse; 3 . a previsão, no contrato, do pagamento do foro; 4 . a lavratura de escritura pública, que é a forma

2. João de Freitas Gouveia, A Enfiteuse e a Política Atual, RT: 529/281. 
exigida para o contrato da enfiteuse; e 5. a previsão de que esse contrato (escritura) seja de caráter perpétuo e seja inscrito no Cartório de Registro do Imóveis, para poder valer contra terceiros.

Nota-se que se o pretenso senhorio não é proprietário do imóvel ou sobre ele não constituiu enfiteuse, regular e formalmente, é ilegal a cobrança de laudêmio. ${ }^{3}$

4. Direitos e deveres do enfiteuta

O enfiteuta, possuidor direto da coisa alheia, pode usar, fruir e até dispor dessa mesma coisa.

Neste sentido, pode vender o imóvel, dá-lo em pagamento, permutá-lo por objeto fungível ou infungível, transmiti-lo por herança ou legado, doá-lo graciosamente, convertê-lo em dote, bem como pode o imóvel se prestar à penhora.

Relevante notar, ainda, o direito do enfiteuta ao resgate ou remição do aforamento mediante o pagamento de um laudêmio, e de dez pensões anuais, dez anos após a constituição da enfiteuse, valendo notar que o foreiro, quando resgata, nada mais faz do que adquirir o imóvel enfitêutico, tornando-se dele proprietário (plena in re potestas).

É, ainda, direito do enfiteuta de ser preferido, em relação a terceiros, no caso de querer o senhorio vender o domínio ou dá-lo em pagamento (Código Civil, art. 684).

A principal obrigação do enfiteuta é o pagamento ao senhorio direto do foro, também denominado cânon, pensão ou aluguel, e do laudêmio. O primeiro, o foro, de valor certo e invariável, é contraprestação anual paga pelo foreiro ao senhorio, para o exercício do domínio útil sobre o imóvel aforado; o segundo, o laudêmio, é a porcentagem de 2,5\% calculada sobre o valor atualizado da propriedade plena, que o enfiteuta paga ao senhorio toda vez que alienar, onerosamente, o bem emprazado.

É, também, obrigação do foreiro arcar com o pagamento dos tributos que recaírem sobre o imóvel aforado.

Deve, ainda, o foreiro conservar a coisa e cuidar dela como se sua fosse, pois poderá o imóvel retornar à plena propriedade do senhorio direto. 
Do mesmo modo, deve o foreiro dar aviso prévio ao senhorio direto, para que exerça direito de opção, se for vender ou dar em pagamento o domínio útil, havendo o senhorio direto de declarar por escrito, se, pelo mesmo preço e nas mesmas condições, quer a preferência na alienação (Código Civil, art. 683).

Obriga-se, ainda, o enfiteuta a manter a indivisibilidade do terreno foreiro, exceto se na divisibilidade consentir o senhorio direto. Neste sentido, pertencendo o imóvel enfitêutico a várias pessoas, devem estas, em seis meses, eleger um cabecel, que é o responsável perante o senhorio pela cobrança de todos os direitos e foros dos demais, caso contrário terá o senhorio direito de realizar essa escolha. Essa pluralidade de foreiros pode ocorrer com a morte do enfiteuta, restando condôminos.

5. Direitos e deveres do senhorio direto

O direito mais visível do senhorio direto é o de receber o cânon ou foro, também chamado de pensão ou aluguel, devido anualmente.

Do mesmo modo, é direito do nu-proprietário receber, na oportunidade do resgate da enfiteuse, o pagamento de um laudêmio, mais dez pensões anuais.

É, também, direito do senhorio direto o de readquirir a propriedade integral, se o enfiteuta cair em comisso ou se falecer sem sucessores. Vale observar que cair em comisso equivale ao fato de extinguir-se o aforamento pelo motivo de o foreiro deixar de pagar a pensão devida por três anos consecutivos.

É, igualmente, direito do nu-proprietário o de ser preferido, em relação a terceiros, no caso do enfiteuta querer alienar o terreno foreiro.

Se, por dívidas contraídas pelo enfiteuta, restar penhorado o imóvel, deverá ser citado o senhorio direto, na ação de execução, pois este tem direito de não-só assistir à praça como de arrematar o bem aprazado.

Dever fundamental do senhorio direto é o de respeitar o domínio útil do foreiro, assegurando a continuidade da enfiteuse. 
6. Formas de extinção da enfiteuse

Apesar da perpetuidade, extingue-se a enfiteuse de vários modos:

a. pelo abandono $o_{2}$ tendo em vista que o foreiro tem o direito de abandonar o bem, gratuita e voluntariamente, ao senhorio direto, cujo ato equivale à renúncia e deve ser inscrito no Registro Imobiliário;

b. pela natural deterioração de bem enfitêutico, se esta situação vier a impedir que o foreiro obtenha da exploração capital equivalente ao cânon e mais um quinto deste;

c. pelo comisso, que é o caso mais comum de extinção, consistente no fato de o foreiro deixar de pagar o aluguel devido por três anos consecutivos. Todavia a aplicação do comisso depende de sentença judicial e o enfiteuta pode purgar a mora enquanto o comisso não tiver sido decretado por sentença;

d. pelo falecimento do enfiteuta sem herdeiros;

e. pela confusão, quando se reunirem, na mesma pessoa, as condições opostas de senhorio e de foreiro, tal acontecendo, por exemplo, se este se tornar herdeiro daquele;

f. pelo resgate, pois, como vimos acima, o enfiteuta, ao exercer o direito de resgate, adquire o imóvel, tornando-se dele plenamente proprietário;

g. pela desapropriação ${ }_{\perp}$ em que se reúnem em uma só pessoa as qualidades de enfiteuta e senhorio direto;

Em decisão perante a $4^{a}$ Câmara de Direito Público do Egrégio Tribunal de Justiça do Estado de São Paulo, por votação unânime, no processo em que são partes, de um lado a Fábrica da Igreja Nossa Senhora D’Ajuda de Caçapava, representada pelo senhor bispo diocesano de Taubaté, do outro a Sabesp, ficou assentado, a propósito de desapropriação, o direito que tem o senhorio direto, no caso a referida paróquia, de receber o laudêmio, mais dez pensões anuais, a título de indenização que será retirada do valor total fixado para o imóvel na sentença. ${ }^{4}$

h) pelo usucapião $o_{1}$ quando o senhor direto ou um terceiro possua $o$ imóvel por tempo suficiente para operar-se a prescrição aquisitiva. ${ }^{5}$

4. J.T.J. - LEX212/200.

5. Giselda Maria F. N. Hironaka, Enfiteuse, Revista Jurídica, n. 21, 1998, Faculdade de Direito de Bauru, p. 37. 
Segundo entendimento jurisprudencial, "dar-se-á, com efeito, a prescrição aquisitiva quando um estranho toma o lugar do foreiro e, em seu lugar, passa à ocupação do imóvel gravado de enfiteuse, como se fosse seu, durante vinte anos ininterruptos, pagando, inclusive, os foros ao senhorio direto" 6

\section{Conclusão}

Já destacamos a necessidade da revitalização do instituto da enfiteuse, porquanto o Brasil nunca precisou tanto como hoje de promover o cultivo das terras improdutivas e o incentivo à agricultura.

Desafortunadamente, não é preciso sair do Estado de São Paulo para contemplar extensas áreas de terras, que não são cultivadas e onde, quando muito, se vêem algumas poucas cabeças de gado a pastar. Essa visão desoladora teve o subscritor destas linhas, em muitas oportunidades, quando, em sua função de juiz de Direito, trabalhou em comarcas no Oeste do Estado.

O alcance social do instituto é incontestável, se verificarmos que muitos municípios brasileiros devem sua existência à aplicação da enfiteuse. Emigrantes italianos e de outras nacionalidades em muito contribuíram para a colonização de vastas áreas deste País, graças, sem dúvida, ao incentivo que receberam em poder dispor de um pedaço de terra para plantar e erguer suas casas, vindo, mais tarde, a se tornarem proprietários daquelas áreas, nos moldes do aforamento, como demonstram os seguidos acenos, nesse sentido, na novela "Terra Nostra" da TV Globo.

No entanto, a sobrevivência do instituto, nos dias atuais, depende nãosó de uma divulgação eficaz e inteligente, mas de uma remodelação e adaptação às condições da vida moderna, de modo a incentivar proprietários e não-proprietários a esse tipo de contrato, tal como preconizado por João de Freitas Gouveia. ${ }^{7}$

Salienta, com propriedade, o referido autor dois aspectos de inegável relevância na revitalização do instituto, quais sejam: 1. Formação de núcleos residenciais e coloniais para povoamento das terras do País, dentro da vasta dimensão territorial brasileira, visando até mesmo à defesa da soberania nacional; 2 . Chamamento, incentivo e fixação do homem ao campo, que acarretará no

6. Edgar Carlos de Amorim, Teoria e Prática da Enfiteuse, Edit. Forense, 1986, p. 37.

7. João de Freitas Gouveia, op. cit. 
esvaziamento das grandes metrópoles, o que, por si só, representaria um feito sem precedentes.

Vejamos algumas sugestões inspiradas nas razões acima:

1. O foro deverá ser reajustado, periodicamente, devido à desvalorização da moeda;

2. Isenção de todos os encargos tributários em relação ao proprietário e ao enfiteuta (à exceção do imposto de transmissão inter vivos);

3. Aumento do percentual do laudêmio, excluído o valor das benfeitorias realizadas pelo enfiteuta;

4. Aumento do prazo máximo para o resgate, passando de dez para quinze ou vinte anos;

5. Incidência de juros e correção monetária nos casos de mora por parte e culpa do enfiteuta no pagamento do foro;

6. Fixação da forma e modo de pagamento do foro, visando à quitação por semestre ou trimestre (o proprietário, no regime atual, é obrigado a esperar um ano todo para receber o foro);

7. O enfiteuta poderá ser notificado, extrajudicialmente, para ser constituído em mora, caso não honre as obrigações contratuais assumidas;

8. Possibilitar a constituição da enfiteuse por meio de contrato particular;

9. Dar maior divulgação ao instituto, mostrando seus benefícios e vantagens;

10. Poderia ser contado para efeito de usucapião extraordinário, em determinados casos, o tempo de posse decorrente do aforamento.

São Paulo, dezembro de 1999. 